\title{
Computational Complexity Reduction of OFDM Signals by PTS with Alternate Optimised Grouping Phase Weighting Method
}

\author{
Prashant Pandey \\ Student Member, IEEE \\ Department of Electronics and \\ Communication, \\ Motilal Nehru National Institute \\ of Technology, Allahabad.
}

\author{
Rajeev Tripathi \\ Member, IEEE \\ Professor, \\ Motilal Nehru National Institute \\ of Technology, Allahabad.
}

\begin{abstract}
Partial Transmit Sequence (PTS) technique is an attractive technique for peak-to-average power ratio (PAPR) reduction of orthogonal frequency division multiplexing (OFDM) signals. However, optimum PTS (OPTS) requires an exhaustive search over all combinations of allowed phase weighting factors, resulting in high computational complexity. In this paper, we propose an Alternate Optimised Grouping Phase Weighting (AO-GPW) method to reduce the computational complexity for PTS. Theoretical analysis and simulation results show that, compared with O-PTS and PTS employing GPW, PTS with AO-GPW method reduces the computational complexity but at the cost of loss of performance for PAPR reduction.
\end{abstract}

\section{General Terms}

Orthogonal Frequency Division Multiplexing (OFDM) System.

\section{Keywords}

Complementary cumulative distribution function (CCDF), Partial Transmit Sequence (PTS), Peak -to-Average Power Ratio.

\section{INTRODUCTION}

Orthogonal frequency division multiplexing (OFDM) has been chosen as the modulation scheme for various communication applications such as digital audio broadcasting (DAB) [1], digital video broadcasting (DVB) [2],[3] and wireless local area networks (WLANs) [4]. However, the major disadvantage associated with OFDM signals is the high peak-to-average power ratio (PAPR) of transmitted signals. This large PAPR causes high bit rate (BER) and adjacent channel interference.

To avoid the occurence of large PAPR of OFDM signals, various schemes for PAPR reduction have been presented such as clipping and filtering [5]-[8], partial transmit sequence [9]-[16], selected mapping [17]-[23], coding schemes [24][28], nonlinear companding transforms [29]-[31], tone reservation (TR) and tone injection (TI) [32]-[33]. Among all existing schemes, partial transmit sequences (PTS) [34] is an important technique because of its good PAPR reduction performance without any signal distortion. But, it is a complex issue to search one OFDM sequence with the minimum PAPR because optimal PTS (O-PTS) requires an exhaustive search over all combinations of allowed phase weighting factors and its computational complexity increases exponentially with the number of subblocks. Some modifications have been proposed in PTS scheme [35]. However, for these schemes, either the performance in PAPR reduction is suboptimal or the computational complexity is still high.

In this paper, we propose a phase weighting method for PTS, named as alternate optimized grouping phase weighting method [34], [36]-[37]. Its aim is to reduce the computational complexity compared to O-PTS and PTS with GPW. However the proposed scheme has some loss in PAPR reduction performance.

This paper is organised as follows. In Section 2, we present the OFDM system model, definition of the PAPR and the definition of the CCDF. In Section 3, we have described optimal PTS and grouping phase weighting method for PTS. Section 4 introduces proposed alternate optimized grouping phase weighting (AO-GPW) method for PTS. In section 5, the performance of proposed phase weighting method is discussed and the simulation and numerical results are shown. Finally, we end the paper with brief conclusions in Section 6.

\section{PAPR IN OFDM SYSTEM}

\subsection{OFDM System Model}

In OFDM system, a block of $\mathrm{N}$ symbols $\mathrm{X}=\left\{\mathrm{X}_{\mathrm{K}}, \mathrm{k}=0,1\right.$, ....., N-1 $\}^{\mathrm{T}}$ is formed with each symbol modulating one of a set of subcarriers, $\left\{\mathrm{f}_{\mathrm{k}}, \mathrm{k}=0,1,2, \ldots \ldots \ldots, \mathrm{N}-1\right\}$ where $\mathrm{N}$ is the number of subcarriers. The $\mathrm{N}$ subcarriers are chosen to be orthogonal, i.e. $\mathrm{f}_{\mathrm{k}}=\mathrm{k} \Delta \mathrm{f}$ where $\Delta \mathrm{f}=1 /(\mathrm{NT})$ and $\mathrm{T}$ is the original symbol period. Now, the complex envelope of the transmitted OFDM signals can be written as,

$$
\mathrm{x}(\mathrm{t})=\frac{1}{\sqrt{\mathrm{N}}} \sum_{\mathrm{k}=0}^{\mathrm{N}-1} \mathrm{X}_{\mathrm{k}} \mathrm{e}^{\mathrm{j} 2 \pi \mathrm{f}_{\mathrm{k}} \mathrm{t}}, 0 \leq \mathrm{t} \leq \mathrm{NT}
$$

where $\mathrm{j}=\sqrt{-1}$

\subsection{PAPR in OFDM System}

In general, the PAPR of OFDM signals $x(t)$ is defined as the ratio of the maximum instantaneous power and its average power 


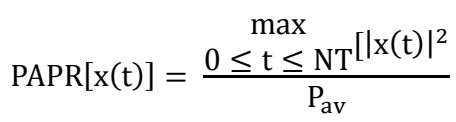

Where $\mathrm{P}_{\mathrm{av}}$ is the average power of $x(t)$ and is given by:

$$
\mathrm{P}_{\mathrm{av}}=\frac{1}{\mathrm{NT}} \int_{0}^{\mathrm{NT}}|\mathrm{x}(\mathrm{t})|^{2} \mathrm{dt}
$$

\subsection{The CCDF of the PAPR}

The complementary cumulative distribution function (CCDF) of the PAPR is the most frequently used performance measure for PAPR reduction techniques. The CCDF of the PAPR denotes the probability that the PAPR of a data block exceeds a given threshold $\gamma$. When the number of the subcarriers $N$ is relatively small, the CCDF expression of the PAPR of OFDM signals can be expressed as

$$
\operatorname{Prob}\{\text { PAPAR }>\gamma\}=1-\left(1-\mathrm{e}^{-\gamma}\right)
$$

\section{OPTIMAL PTS (O-PTS) and GPW for PTS}

\subsection{The PTS Technique}

In PTS, as shown in fig. 1, an input data block of $\mathrm{N}$ symbols is partitioned into $\mathrm{M}$ disjoint subblocks, which are transformed into $\mathrm{M}$ time-domain partial transmit sequences. These partial sequences are independently rotated by phase factors. The objective of this approach is to optimally combine the subblocks to obtain the time domain OFDM signals with the lowest PAPR.

\subsection{Mathematical Model for the O-PTS Technique}

In O-PTS, the input data sequence of an OFDM system with $\mathrm{N}$ subcarriers is firstly partitioned into $\mathrm{M}$ disjoint subblocks $\mathrm{X}_{\mathrm{i}}, \mathrm{i}=1,2, \ldots, \mathrm{M}$, where all the subcarriers which are occupied by the other subblocks are set to zero. The frequency domain input sequence is given as

$$
X=\sum_{i=1}^{M} X_{i}
$$

By applying a phase weighting factor $\mathrm{b}_{\mathrm{i}}=\exp \left(\mathrm{j} \Phi_{\mathrm{i}}\right), \Phi_{\mathrm{i}} \in[0$, $2 \pi)$ to the $i^{\text {th }}$ subblock $X_{i}=\left[X_{i, 1}, X_{i, 2}, \ldots \ldots \ldots, X_{i, N}\right]^{T}, i=1,2$, ......, $\mathrm{M}$, alternative frequency signal sequence is given as

$$
\mathrm{X}^{\prime}=\sum_{\mathrm{i}=1}^{\mathrm{M}} \mathrm{b}_{\mathrm{i}}
$$

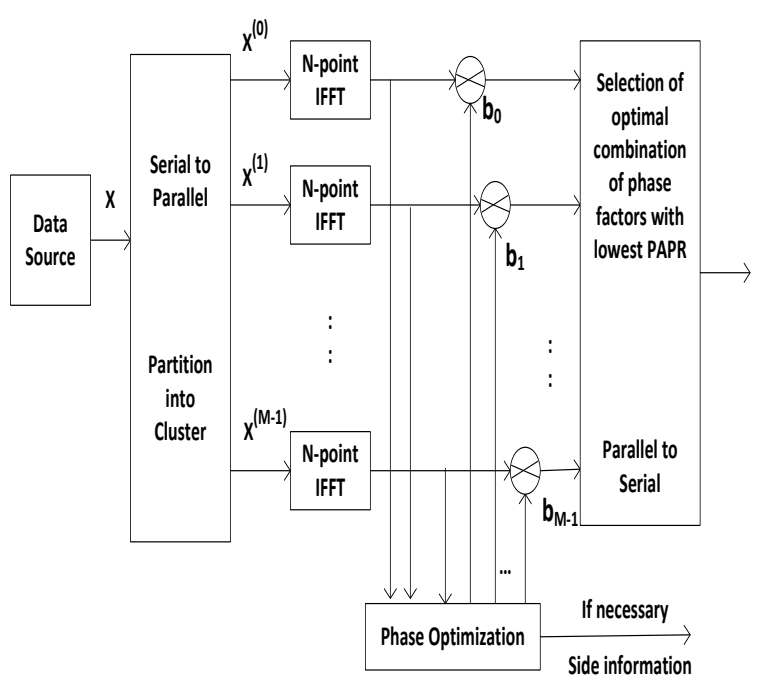

Figure 1: Block Diagram of the PTS Technique

After being transformed to time domain by IFFT, the time domain signal sequence becomes

$$
\mathrm{x}^{\prime}=\operatorname{IFFT}\left\{\sum_{\mathrm{i}=1}^{\mathrm{M}} \mathrm{b}_{\mathrm{i}} \mathrm{X}_{\mathrm{i}}\right\}=\sum_{\mathrm{i}=1}^{\mathrm{M}} \mathrm{b}_{\mathrm{i}} . \operatorname{IFFT}\left\{\mathrm{X}_{\mathrm{i}}\right\}=\sum_{\mathrm{i}=1}^{\mathrm{M}} \mathrm{b}_{\mathrm{i}} \mathrm{x}_{\mathrm{i}}
$$

In the above equation, $\mathbf{x}^{\prime}$ denotes the candidate sequence.

For generating different phase weighting sequences, a set of phase weighting factors is normally chosen. Assuming that there be $\mathrm{W}$ allowed phase weighting factors in this set. Without any loss of performance, we can set phase weighting factor for the first subblock to one and we see that there are (M-1) subblocks to be optimized. It is obvious that $\mathrm{W}^{\mathrm{M}-1}$ combinations must be checked to find the optimum candidate sequence with the minimum PAPR. For optimal PTS (OPTS), the optimum PAPR performance can be got after searching $\mathrm{W}^{\mathrm{M}-1}$ possible alternative combinations where $\mathrm{M}$ is the number of subblocks and $\mathrm{W}$ is the number of allowed phase weighting factors. In the process of phase weighting combination, large number of complex multiplications are needed and hence the computational complexity is very large.

\subsection{Group Phase weighting (GPW) for PTS}

In order to reduce the computational complexity compared to O-PTS, GPW has been proposed in [34]. It offers same PAPR reduction performance with respect to O-PTS. In GPW, all the subblocks are split into several groups, and each group can obtain its own subcandiate sequence by using the same set of phase weighting factors; then, subcandidate sequences from different groups are combined to generate all the OFDM candidate sequences. Thereafter, that candidate sequence is selected for transmitting which has the minimum PAPR.

\section{ALTERNATE OPTIMISED GROUPING PHASE WEIGHTING} 5. (AO-GPW) METHOD

In this proposed approach, alternate optimization is used in group phase weighting method for PTS. 


\subsection{Mathematical Model For the AO-GPW Method}

The OFDM candidate sequence given in (7) can be written as

$$
\begin{gathered}
\mathrm{x}^{\prime}=\sum_{\mathrm{i}=1}^{\mathrm{M}} \mathrm{b}_{\mathrm{i}} \mathrm{x}_{\mathrm{i}}=\sum_{\mathrm{i}=1}^{\mathrm{r}_{1}} \mathrm{~b}_{\mathrm{i}} \mathrm{x}_{\mathrm{i}}+\sum_{\mathrm{i}=\mathrm{r}_{1}+1}^{\mathrm{r}_{2}} \mathrm{~b}_{\mathrm{i}} \mathrm{x}_{\mathrm{i}}+\cdots+\sum_{\mathrm{i}=\mathrm{r}_{\mathrm{R}-1}+1}^{\mathrm{M}} \mathrm{b}_{\mathrm{i}} \mathrm{x}_{\mathrm{i}} \\
1<\mathrm{r}_{1}<\mathrm{r}_{2} \ldots \ldots \ldots \ldots \ldots<\mathrm{r}_{\mathrm{R}-1}<\mathrm{V}
\end{gathered}
$$

where the value of $r_{i}, i=1,2, \ldots \ldots, R-1$ is the index of subblock. It can be observed in the above equation that all the subblocks can be divided into several groups, and for each group, phase weighting process can be implemented by itself. Here, we define $R$ to be number of groups, $G_{k}, k=1,2, \ldots, R$ to be the number of subcadidate sequence from the $\mathrm{k}^{\text {th }}$ group. The number of subblocks in each group can be expressed by $r_{1}, r_{2}-r_{1}, r_{3}-r_{2}, \ldots . . ., M-r_{R-1}$, where $r_{1}$ must be bigger that one (because phase weighting factor for the first subblock is constant). So Equation (8) can be written as

$$
\begin{aligned}
\mathrm{x}^{\prime}= & \sum_{\mathrm{i}=1}^{\mathrm{M}} \mathrm{b}_{\mathrm{i}} \mathrm{x}_{\mathrm{i}}= \\
& \sum_{\mathrm{i}=\mathrm{r}_{0}}^{\mathrm{r}_{1}} \mathrm{~b}_{\mathrm{i}} \mathrm{x}_{\mathrm{i}}+\sum_{\mathrm{i}=\mathrm{r}_{1}+1}^{\mathrm{r}_{2}} \mathrm{~b}_{\mathrm{i}} \mathrm{x}_{\mathrm{i}}+\ldots \ldots+\sum_{\mathrm{i}=\mathrm{r}_{\mathrm{R}-1}+1}^{\mathrm{r}_{\mathrm{R}}} \mathrm{b}_{\mathrm{i}} \mathrm{x}_{\mathrm{i}} \\
= & \mathrm{G}_{1}+\mathrm{G}_{2}+\ldots \ldots \ldots \ldots+\mathrm{G}_{\mathrm{R}} \\
& 1=\mathrm{r}_{0}<\mathrm{r}_{1}<\mathrm{r}_{2}<\ldots \ldots \ldots<\mathrm{r}_{\mathrm{R}-1}<\mathrm{r}_{\mathrm{R}}=\mathrm{M}
\end{aligned}
$$

By making use of the same set of phase weighting factors, groups $\mathrm{G}_{\mathrm{i}}{ }^{\text {s }}, \mathrm{i}=1,2, \ldots \ldots, \mathrm{R}$ can implement their respective phase weighting processes and obtain their respective subcandidate sequences. Thereafter, subcandidate sequences from these different groups can be combined using complex additions to achieve all the OFDM candidate sequences, and the one with the minimum PAPR is selected for transmission.

We modify the above model such that within each group $G_{i}$, we implement alternate optimization, i. e. within a group, starting from the first subblock, every alternate subblock is kept unchanged and the phase factors are optimized only for the rest of the subblocks. Thus, different from that in GPW, here within a group, phase weighting factors are needed only for half of the subblocks. In this way, the computational complexity is reduced clearly but at the cost of loss of performance for PAPR reduction.

\subsection{Example}

When the number of subblocks $M=4$, the set of phase weighting factors is $\{1,-1\}$ (i.e. $W=2$ ), the number of groups $\mathrm{R}=2$ and there are two subblocks in the first group, so the four subblocks can be divided into two groups: one includes the first two subblocks, and the other includes the rest ones. Phase weighting sequences for each group are shown as follows.

$$
\begin{gathered}
\text { First Group: }[1,1]^{\mathrm{T}},[1,-1]^{\mathrm{T}} \\
\text { Second Group: }[1,1]^{\mathrm{T}},[1,-1]^{\mathrm{T}}
\end{gathered}
$$

Hence, subcandidate sequences from the first group $G_{1,1}=$ $x_{1}+x_{2}, G_{1,2}=x_{1}-x_{2}$, and subcandidate sequences from the second group $G_{2,1}=x_{3}+x_{4}, G_{2,2}=x_{3}-x_{4}$, can be obtained by employing the above phase weighting sequences, respectively, where $\mathrm{G}_{\mathrm{p}, \mathrm{q}}$ denotes the $q^{\text {th }}$ subcandidate sequence from the $p^{\text {th }}$ group. Here we see that alternate optimization is implemented in both the groups i.e. within both the groups the first subblock remains unchanged while phase factors are optimized only for the rest of the subblocks. Finally, subcandidate sequences from the first group are combined with the ones from the second group. Hence, we obtain four OFDM candidate sequences $\mathrm{Y}_{\mathrm{i}}, \mathrm{i}=1,2, \ldots . .4$ as follows:

$$
\begin{aligned}
& Y_{1}=G_{1,1}+G_{2,1}=x_{1}+x_{2}+x_{3}+x_{4}, \\
& Y_{2}=G_{1,1}+G_{2,2}=x_{1}+x_{2}+x_{3}-x_{4}, \\
& Y_{3}=G_{1,2}+G_{2,1}=x_{1}-x_{2}+x_{3}+x_{4}, \\
& Y_{4}=G_{1,2}+G_{2,2}=x_{1}-x_{2}+x_{3}-x_{4},
\end{aligned}
$$

Now the candidate sequence with the minimum PAPAR is selected for transmitting.

\subsection{Comparison of AO-GPW, GPW and O- PTS}

For AO-GPW method, the phase weighting sequences for both the groups and the OFDM candidate sequences are given in the above example. In GPW method for PTS, under the same configurations, the phase weighting sequences for each group are shown as follows:

First Group: $[1,1]^{\mathrm{T}},[1,-1]^{\mathrm{T}}$

Second Group: $[1,1]^{\mathrm{T}},[1,-1]^{\mathrm{T}},[-1,1]^{\mathrm{T}},[-1,-1]^{\mathrm{T}}$

We can obtain eight OFDM candidate sequences $Y_{i}^{\prime}, i=$ $1,2, \ldots \ldots, 8$ as follows:

$$
\begin{aligned}
& Y_{1}^{\prime}=x_{1}+x_{2}+x_{3}+x_{4}, \\
& Y_{2}^{\prime}=x_{1}+x_{2}+x_{3}-x_{4}, \\
& Y_{3}^{\prime}=x_{1}+x_{2}-x_{3}+x_{4}, \\
& Y_{4}^{\prime}=x_{1}+x_{2}-x_{3}-x_{4}, \\
& Y_{5}^{\prime}=x_{1}-x_{2}+x_{3}+x_{4}, \\
& Y_{6}^{\prime}=x_{1}-x_{2}+x_{3}-x_{4}, \\
& Y_{7}^{\prime}=x_{1}-x_{2}-x_{3}+x_{4}, \\
& Y_{8}^{\prime}=x_{1}-x_{2}-x_{3}-x_{4},
\end{aligned}
$$

In O-PTS scheme, under the same configurations as that of AO-GPW, all the phase weighting sequences can be given as:

$[1,1,1,1]^{\mathrm{T}},[1,1,1,-1]^{\mathrm{T}},[1,1,-1,1]^{\mathrm{T}},[1,1,-1,-1]^{\mathrm{T}},[1,-1$, $1,1]^{\mathrm{T}},[1,-1,1,-1]^{\mathrm{T}},[1,-1,-1,1]^{\mathrm{T}},[1,-1,-1,-1]^{\mathrm{T}}$

For the above phase weighting sequences, we can have the eight OFDM candidate sequences $Y_{i}^{\prime \prime}, i=1,2, \ldots \ldots \ldots, 8$, given as:

$$
Y_{1}^{\prime \prime}=x_{1}+x_{2}+x_{3}+x_{4}
$$




$$
\begin{aligned}
& Y_{2}^{\prime \prime}=x_{1}+x_{2}+x_{3}-x_{4}, \\
& Y_{3}^{\prime \prime}=x_{1}+x_{2}-x_{3}+x_{4}, \\
& Y_{4}^{\prime \prime}=x_{1}+x_{2}-x_{3}-x_{4}, \\
& Y_{5}^{\prime \prime}=x_{1}-x_{2}+x_{3}+x_{4}, \\
& Y_{6}^{\prime \prime}=x_{1}-x_{2}+x_{3}-x_{4}, \\
& Y_{7}^{\prime \prime}=x_{1}-x_{2}-x_{3}+x_{4}, \\
& Y_{8}^{\prime \prime}=x_{1}-x_{2}-x_{3}-x_{4},
\end{aligned}
$$

As for computational complexity, each element in phase weighting sequence means that $\mathrm{LN}$ complex multiplications are needed, where $\mathrm{L}$ is the oversampling factor. Thus, any phase weighting sequence which contains fewer elements will have lower computational complexity for generating one candidate sequence. It can be seen from the above discussion that the proposed scheme (AO-GPW) has four phase weighting sequences and the number of elements in each sequence is two; however for GPW, six phase weighting sequences are generated and the number of elements in each sequence is two; while in O-PTS, eight phase weighting sequences are generated and the number of elements in each sequence is four. Thus, under the same configurations, the number of phase weighting sequences is lesser in AO-GPW as compared to GPW and O-PTS

Thus, in AO-GPW due to alternate optimization we have lesser computational complexity as compared to GPW, while GPW has lesser computational complexity as compared to OPTS (because GPW has lesser number of phase weighting sequences and lesser number of elements in each phase weighting sequence).

Also, as regards to PAPR reduction issue, it can be seen from (10), (11), (12) that PTS with AO-GPW has four OFDM candidate sequences while PTS with GPW and O-PTS have eight OFDM candidate sequences.

Thus the proposed scheme has drawback that it has lesser number of choices available for selecting the optimum candidate sequence than GPW and O-PTS methods. Thus the proposed scheme has drawback that it has lesser PAPR reduction capability as compared to GPW and O-PTS methods.

Hence, we see that computational complexity of the AO-GPW is lesser as compared to GPW and O-PTS while the PAPR reduction capability of this proposed method is lesser as compared to GPW and O-PTS method.

\section{PERFORMANCE ANALYSIS AND SIMULATION RESULTS}

\subsection{Performance Analysis}

The advantage in AO-GPW is that it has lesser computational complexity than GPW and O-PTS but the disadvantage is that it has lesser PAPR reduction capability than GPW and O-PTS.

\subsection{Simulation Results}

In this section, we do extensive simulations to verify the performance of the proposed schemes. For our simulation following parameters have been used.

Table 1 : Simulation Parameters

\begin{tabular}{|l|l|}
\hline $\begin{array}{l}\text { Number of OFDM blocks for } \\
\text { iteration }\end{array}$ & 3000 \\
\hline No. of Subcarriers (N) & $128,256,512$ \\
\hline No. of disjoint subblocks (M) & 4 \\
\hline Oversampling factor (L) & 4 \\
\hline Modulation type & QPSK \\
\hline No. of phase weighting factors & 2 \\
\hline The set of phase weighting factors & $\{1,-1\}$ \\
\hline
\end{tabular}

For PAPR reduction performance, the CCDF is used to evaluate and compare the performance of any PAPR reduction schemes. Figure 2, 3 and 4 show performance comparison between the original OFDM, AO-GPW method and GPW method. As is Obvious from the figures AO-GPW method has lesser PAPR reduction capability than that of the GPW method which is the disadvantage as stated in the theoretical analysis. Also it is evident from the figures that PAPR reduction capability decreases as we increase the number of subcarriers. 


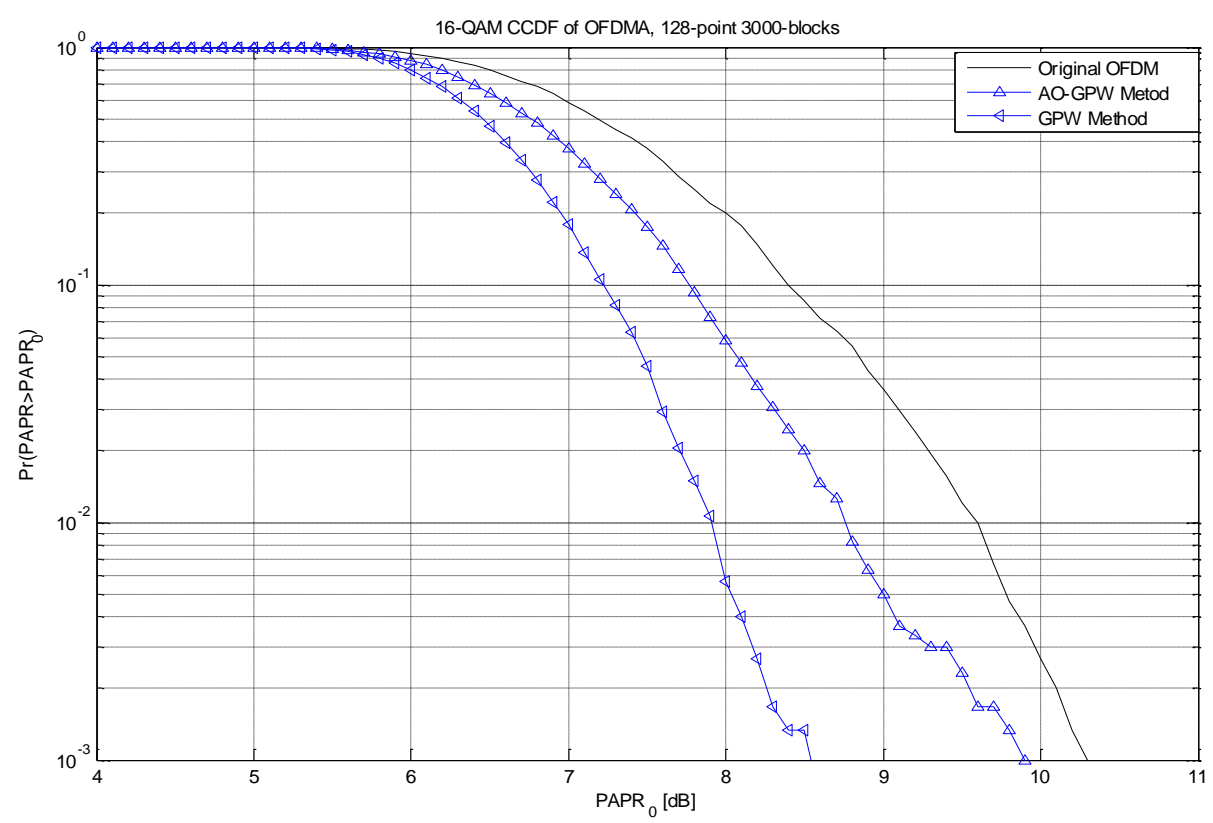

Figure 2: Comparison of CCDF of PAPR of PTS with AO-GPW, GPW and Original OFDM Signal (N=128)

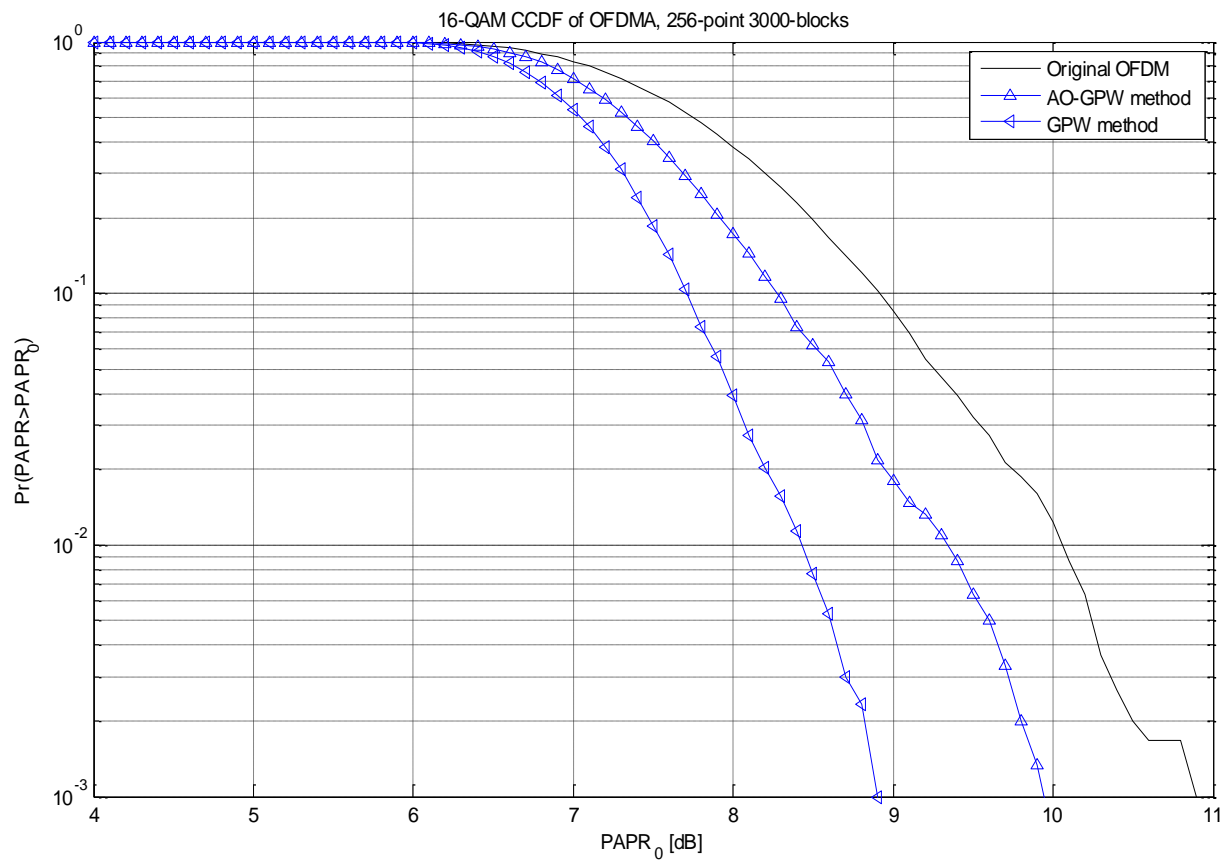

Figure 3: Comparison of CCDF of PAPR of PTS with AO-GPW, GPW and Original OFDM Signal (N=256) 


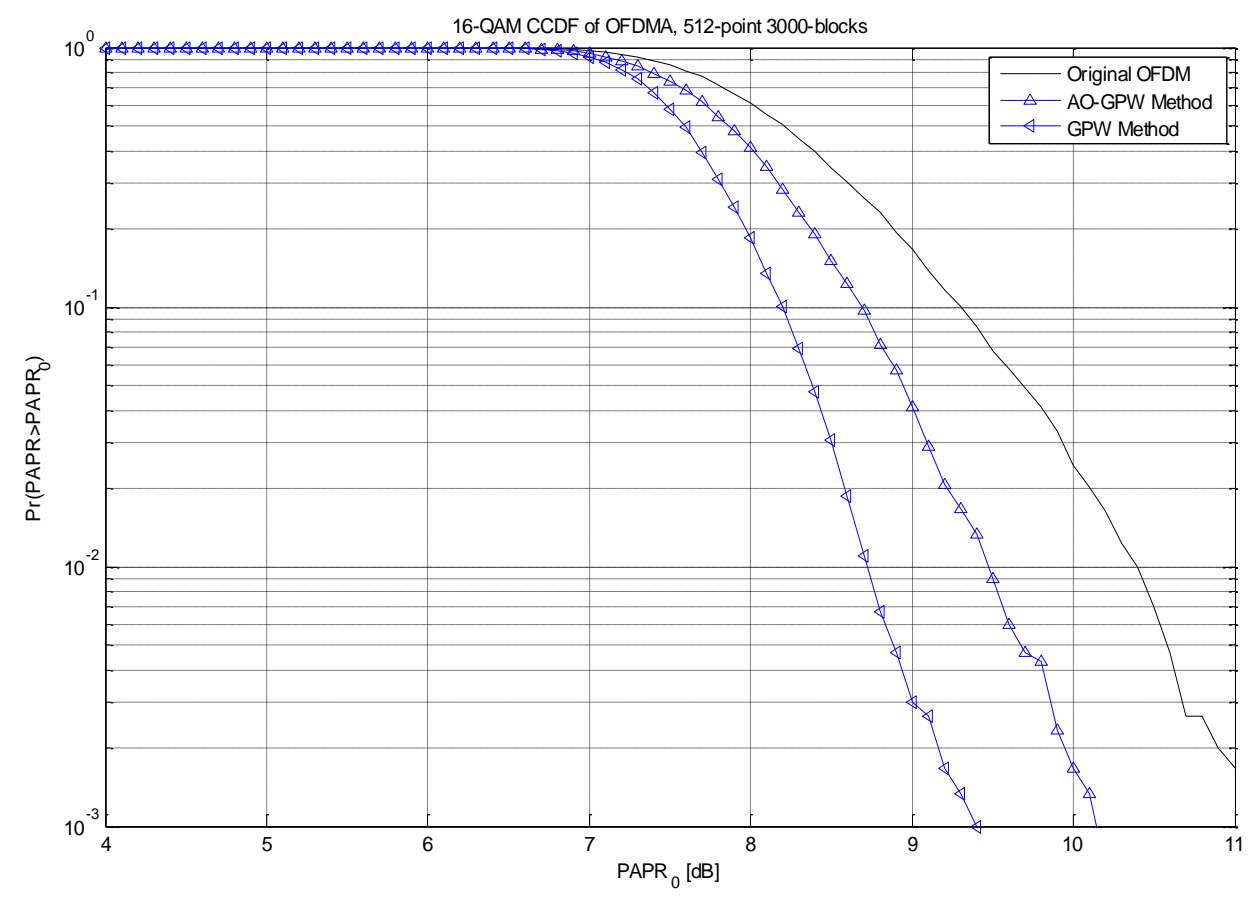

Figure 4: Comparison of CCDF of PAPR of PTS with AO-GPW, GPW and Original OFDM Signal (N=512)

\section{CONCLUSIONS}

In this paper, a phase weighting method with low computational complexity for PTS is proposed. This method (AO-GPW) has lesser computational complexity as compared to existing methods viz. GPW and O-PTS. However it has the drawback that its PAPR reduction capability is lesser as compared to GPW and O-PTS methods. Hence the computational complexity is reduced but at the cost of PAPR reduction performance.

\section{REFERENCES}

[1] Wu Y. and Zou W. Y., "Orthogonal frequency division multiplexing: A multi-carrier modulation scheme," IEEE Trans. Consum. Electron., Aug. 1995, 41, (3), pp. 392399.

[2] Zou W. Y. and Wu Y., "COFDM: An overview," IEEE Trans. Broadcast., Mar. 1995, 41, (1), pp. 1-8.

[3] Reimers, U. "Digital Video Broadcasting", IEEE Commn. Mag., June 1998, 36, (6), pp. 104-110.

[4] Institute of Electrical and Electronics Engineers, IEEE Standard 802.11a: Wireless LAN Medium Access Control (MAC) and Physical Layer (PHY) Specifications: HighSpeed Physical Layer in the 5 GHz Band, 1999.

[5] Neill R. O' and Lopes L. N. "Envelope variations and spectral splatter in clipped multicarrier signals," in Proc. PMRC'95, Sept. 1995, pp. 71-75.

[6] Ochiai H. and Imai H., "Performance analysis of deliberately clipped OFDM signals," IEEE Trans. Commun., Jan. 2002, 50, (1), pp. 89-101.
[7] Ju S. M. and Leung S. H., "Clipping on COFDM with phase on demand," IEEE Communications Letters, Feb. 2003, 7, (2), pp. 49-51.

[8] Ren G. L., Zhang H., and Chang Y. L., "A complementary clipping transform technique for the reduction of peak-toaverage power ratio of OFDM system," IEEE Trans. Consumer Electronics, Nov. 2003, 49, (4), pp. 922-926.

[9] Muller S. H. and Huber J. B., "OFDM with reduced peakto-average power ratio by optimum combination of partial transmit sequences," IEE Electronics Letters, Feb. 1997, 33, (5), pp. 36-69.

[10] Han S. H. and Lee J. H. "PAPR reduction of OFDM signals using a reduced complexity PTS technique," IEEE Signal Processing Letters, Nov. 2004, 11, (11), pp. $887-890$

[11] Alavi A., Tellambura C., and Fair I., "PAPR reduction of OFDM signals using partial transmit sequence: An optimal approach using sphere decoding," IEEE Trans. Communications Letters, Nov. 2005, 9, (11), pp. 982 984.

[12] Hieu N. T., Kim S. W., and Ryu H. G., "PAPR reduction of the low complexity phase weighting method in OFDM communication system," IEEE Trans. Consumer Electronics, Aug. 2005, 51, (3), pp. 776-782.

[13] Yang L., Chen R. S., Siu Y. M., and Soo K. K., "PAPR reduction of an OFDM signal by use of PTS with low computational complexity," IEEE Trans. Broadcasting, Mar. 2006, 52, (1), pp. 83-86.

[14] Chen H. and Liang H., "PAPR reduction of OFDM signals using partial transmit sequences and Reed-Muller codes," IEEE Communications Letters, Jun. 2007, 11, (6), pp. 528-530. 
[15] Park D. H. and Song H. K. "A new PAPR reduction technique of OFDM system with nonlinear high power amplifier," IEEE Trans. Consumer Electronics, May 2007, 53, (2), pp. 327-332.

[16] Xiao Y., Lei X., Wen Q., and Li S., "A class of low complexity PTS techniques for PAPR reduction in OFDM systems," IEEE Signal Processing Letters, Oct.

2007, 14, (10), pp. 680-683.

[17] Baxley R. J. and Zhou G. T., "Comparing selected mapping and partial transmit sequence for PAR reduction," IEEE Trans. Broadcasting, Dec. 2007, 53, (4), pp. 797-803.

[18] Heo S. J., Noh H. S., No J. S., and Shin D. J., "A modified SLM scheme with low complexity for PAPR reduction of OFDM systems," IEEE Trans. Broadcasting, Dec. 2007, 53, (4), pp. 804-808.

[19] Lim D. W. , No J. S., Lim C. W., and Chung H., "A new SLM OFDM scheme with low complexity for PAPR reduction," IEEE Signal Processing Letters, Feb. 2005, 12, (2), pp. 93-96.

[20] Wang C. L. and Yuan Q. Y., "Low-complexity selected mapping schemes for peak-to-average power ratio reduction in OFDM systems," IEEE Trans. Signal Processing, Dec. 2005, 53, (12), pp. 4652-4660.

[21] Ryu H. G., Hoa T. P. , Lee K. M. , Kim S. W., and Park J. S. "Improvement of power efficiency of HPA by the PAPR reduction and predistortion," IEEE Trans. Consumer Electronics, Feb. 2004, 50, (1), pp. 119-124.

[22] Han S. H. and Lee J. H., "Modified selected mapping technique for PAPR reduction of coded OFDM signal," IEEE Trans. Broadcasting, 50, (3), pp. 335-341, Sept. 2004.

[23] Bauml R. W., Fisher R. F. H., and Huber J. B., "Reducing the Peak-to-Average Power Ratio of Multicarrier Modulation by Selected Mapping," IEE Electronics Letters, Oct. 1996, 32, (22), pp. 2056-2057.

[24] Jones A. E., Wilkinson T. A., and Barton S. K., "Block coding scheme for reduction of peak-to-average envelope power ratio of multicarrier transmission systems," IEE Electronics Letters, Dec. 1994, 30, (8), pp. 2098-2099.

[25] Fan P. Y. and Xia X. G., "Block coded modulation for the reduction of the peak to average power ratio in OFDM systems," IEEE Trans. Consumer Electronics, Nov. 1999, 45, (4), pp. 1025-1029.
[26] Yang K. and Chang S., "Peak-to-average power control in OFDM using standard arrays of linear block codes," IEEE Communications Letters, Apr. 2003, 7, (4), pp. 174-176.

[27] Jiang T. and Zhu G. X., "Complement block coding for reduction in peak-to-average power ratio of OFDM signals," IEEE Communications Magazine, Sept. 2005, 43, (9), pp. S17-S22.

[28] Slimane S. B., "Reducing the peak-to-average power ratio of OFDM signals through precoding," IEEE Trans. Vehicular Technology, Mar. 2007, 56, (2), pp. 686-695.

[29] Wang X. B., Tjhung T. T., and Ng C. S., "Reduction of peak-to-average power ratio of OFDM system using A companding technique," IEEE Trans. Broadcasting, Sept. 1999, 45, (3), pp. 303-307.

[30] Jiang T. and Zhu G. X., "Nonlinear companding transform for reducing peak-to-average power ratio of OFDM signals," IEEE Trans. Broadcasting, Sept. 2004, 50, (3), pp. 342-346.

[31] Huang X., Lu J. H., Zheng J. L., Letaief K. B., and Gu J., "Companding transform for reduction in peak-to-average power ratio of OFDM signals," IEEE Trans. Wireless Communications, Nov. 2004, 3, (6), pp. 2030-2039.

[32] Tellado J., "Peak to Average Power Ratio Reduction for Multicarrier Modulation," $\mathrm{PhD}$ thesis, University of Stanford, Stanford, 1999.

[33] Yoo S. S., Yoon S., Kim S. Y., and Song I., "A novel PAPR reduction scheme for OFDM systems: Selective mapping of partial tones (SMOPT)," IEEE Trans. Consumer Electronics, Feb. 2006, 52, (1), pp. 40-43.

[34] Wang L. and Liu J., "PAPR Reduction of OFDM Signals by PTS With Grouping and Recursive Phase Weighting Methods, ” IEEE Trans. Broadcast., June 2011, 57, (2), pp. 1-8.

[35] van Nee R. and Prasad R., OFDM for Wireless Multimedia Communications.

[36] Wang L. and Cao Y., "Sub-optimum PTS for PAPR reduction of OFDM signals," Electron. Lett., vol. 44, no. 15, pp. 921-922, Jul. 2008

[37] Pandey P. and Tripathi R., "Performance analysis of peak-to-average power ratio (PAPR) reduction techniques in an OFDM system," in Third IEEE International conference on computer and communication technology (ICCCT), Allahabad, pp. 245-249, Nov. 2012. 